\title{
O ensino da história e da cultura afro-brasileira e o discurso in/exclusivo da diversidade
}

History of education and culture afro-brazilian and discourse in/exclusive diversity

\section{Camila Francisca da Rosa \\ Mozart Linhares da Silva}

Universidade de Santa Cruz do Sul - Unisc - Santa Cruz do Sul - Rio Grande do Sul - Brasil

\begin{abstract}
Resumo: O presente artigo objetiva analisar as legislações que orientam o ensino da História e da Cultura Afro-brasileira no Brasil a partir de um discurso que se restringe à perspectiva da diversidade e anula as problematizações em torno do conceito de diferença. Através das teorizações foucaultianas especialmente a governamentalidade biopolítica, problematizamos as Diretrizes Curriculares Nacionais para Educação das Relações Étnico-Raciais e para o Ensino de História e Cultura Afro-Brasileira e Africana no qual o enunciado da diversidade está imbricado numa lógica de in/exclusão étnico-racial que regula e potencializa um currículo que produz sujeitos subjetivados a uma política multiculturalista de tolerância às identidades e à alteridade.
\end{abstract}

Palavras-chave: Diversidade. Educação. Biopolítica.

\begin{abstract}
This article aims to analyze the laws that guide the teaching of History and Afro-Brazilian culture in Brazil from a discourse that is limited to the perspective of diversity and annuls the problematizations around the concept of difference. Through Foucault's theorizing especially biopolitics governmentality, we problematize the National Curriculum Guidelines for Education of Racial-Ethnic Relations and the Teaching of Afro-Brazilian culture and African in which the statement of diversity is imbricated in a logic in/exclusion racial regulates and enhances a curriculum that produces subjectified subject to a multiculturalist tolerance policy identities and otherness.
\end{abstract}

Keywords: Diversity. Education. Biopolitics. 


\section{Introdução}

Implantada a Lei 10.639 de 2003 que torna obrigatório o Estudo da História e Cultura Afrobrasileira (alterada em 2008 pela Lei 11.645, que incluiu o ensino da História e cultura indígenas) a presença das questões étnico-raciais foram potencializadas no currículo pedagógico brasileiro. A Lei é resultado da emergência dos movimentos negros, nomeadamente o Movimento Negro Unificado (MNU), criado em 1978; do enfrentamento crítico ao "mito" ou "ideologia" da democracia racial; da implantação de uma agenda multiculturalista, entendida como desdobramento de uma política neoliberal, a partir do governo FHC e expandida nos governos Lula. Interessa-nos, neste contexto, para além dos efeitos da obrigatoriedade que a Lei implica, a inclusão de uma educação para o combate ao racismo e valorização da história e cultura negras, questões que apontam para uma reorientação do saber histórico.

Atualmente, o tratamento da temática da Lei 10.639 no currículo escolar é orientado pelas Diretrizes Curriculares Nacionais para Educação das Relações Étnico-Raciais e para o Ensino de História e Cultura Afro-Brasileira e Africana, de 2004, documento que tomamos com corpus discursivo e a partir do qual problematizamos os processos de in/exclusão na contemporaneidade, sobretudo no que diz respeito às questões étnico-raciais.

\section{Democracia racial e educação: o silêncio histórico sobre o racismo}

O chamado mito da democracia racial, ou seja, a ideia de inexistência de preconceito racial ou de cor no Brasil, produziu uma ordem discursiva que despotencializou as problematizações acerca das relações de alteridade. O mito, cuja construção nos remete aos anos 1920-30, a partir de uma nova roupagem das teorias biodeterministas oriundas da Europa e do processo de nacionalização implantado por Getúlio Vargas, tornou-se peça chave para entendermos a construção de uma narrativa da cordialidade e da não-conflitualidade étnico-racial no Brasil.

Desde a tradução das teorias racialistas que adentraram o país a partir a chamada geração de 1870, nomeadamente pelas portas da Escola de Recife, o debate sobre o devir da nação, sobre a formação do corpo-espécie da população, passou a ser norteado pelo discurso científico. Grosso modo, em meio à pluralidade de posturas e ideias que, a partir daquele contexto, passaram a debater sobre a construção nacional, podemos destacar algumas correntes que tiveram significativa influência entre os intelectuais e cientistas da época. A questão central destes debates fora a presença negra e a mestiçagem da população. Desde Silvio Romero (1851-1914) a mestiçagem passou a orientar as lentes interpretativas do Brasil. É em Sílvio Romero, inclusive, que encontramos precocemente uma visão que tomava a miscigenação como positiva, pois que a partir dela se poderia ir gradualmente embranquecendo a população brasileira. A mestiçagem, pelas lentes do racialismo europeu era fator de degeneração e, portanto fenômeno a ser evitado, é o que encontramos naqueles que faziam eco às ideias de Louis Agassiz (1807-1873), Conde Joseph Arthur de Gobineau (1816-1882) e Herbert Spencer (1820-1903), como Nina Rodrigues (18621906) e Euclides da Cunha (1866-1909), autores que marcaram forte influência no final do século XIX e início do século $X X$. Nas duas primeiras décadas do século $X X$, no entanto, o debate sobre raça $\mathrm{e}$ população ganha outras duas proposições, por vezes imbricadas: o sanitarismo e a eugenia. $O$ debate entre o determinismo biológico/racial e os condicionantes do meio deram o tom das discussões neste contexto, marcado pelas ideias lamarckianas que positivavam um melhoramento da população através de medidas que alterassem o meio social e melhorassem os caracteres a serem adquiridos e transmitidos pela hereditariedade. Notórios sanitaristas como Edgar Roquette-Pinto (1884-1954), Arthur Neiva (18801943) e Belisário Pena (1868-1939) tiveram forte atuação na campanha sanitarista, ancorada, a partir de 1918, pela Liga Pró-Saneamento. Soma-se a Liga, 
outra instituição criada no mesmo ano que agrupou intelectuais e cientistas de várias matizes: a Sociedade Eugênica de São Paulo, criada pelo prócere da eugenia brasileira, Renato Kehl (18891974), autor de várias obras de divulgação da ciência de Francis Galton (1822-1911) bem como coordenador de instituições de feição eugenista como o Instituto Brasileiro de Eugenia, conhecido por amparar a publicação do periódico Boletim de Eugenia (editado entre 1929 e 1933). O movimento eugenista capitaneado por Kehl teve seu momento áureo com a organização, em 1929, do Primeiro Congresso Brasileiro de Eugenia, onde marcaram presença os mais atuantes e importantes cientistas e intelectuais brasileiros ${ }^{1}$.

Dentre as diversas teses sobre o futuro da raça/população brasileira, que não trataremos nos limites deste artigo, destaca-se a versão do cientista e coordenador do Museu Nacional, Batista de Lacerda (1846-1915). Lacerda foi enviado oficial ao Congresso Universal das Raças, realizado em 1911 na cidade de Londres, ocasião em que proferiu a famosa e lapidar conferência Sur le métis au Brésil ([1911] 2011). Nesta conferência Lacerda defendeu a tese da miscigenação como elemento redentor do Brasil, pois ao contrário das visões pessimistas atinentes às teses da degeneração provocada pela mestiçagem, o cientista propôs a miscigenação como processo de branqueamento da população. Segundo Lacerda (1912, p. 94-95), "provavelmente antes de um século a população do Brasil será representada, na maior parte, por indivíduos de raça branca, latina, e para a mesma época o negro e o índio terão certamente desapparecido desta parte da América". A conferência marca uma tomada de posição oficial do Estado brasileiro que, a partir daquele contexto, começa a articular gradativamente um discurso que positiva a miscigenação como fenômeno civilizatório, pois que a partir dela a população brasileira poderia embranquecer, condição sine qua non para o devir da nação.

\footnotetext{
1 Ver sobre o Congresso as Actas e trabalhos do Primeiro Congresso Brasileiro de Eugenia. Rio de Janeiro: Faculdade de Medicina, 1933.
}

O branqueamento gradual do corpo-espécie da população ocorreria através da miscigenação e do estímulo à entrada de imigrantes eugênicos. E o fenômeno da mestiçagem concretiza-se como um processo benéfico, mas, acima de tudo, transitório, a vista de seus entusiastas.

Tão logo, superado o discurso pessimista quanto o futuro da nação brasileira, o momento, de acordo com Schwarcz, "parecia propício para arriscar explicações de ordem cultural sobre esse país que ainda se via como um ponto de interrogação" (2012, p. 47). Para além da mestiçagem sobre o viés biológico, emerge também um projeto nacionalista que faz uso cultural do termo. É com o governo Varguista (1930-1945) que, com efeito, haverá a construção de um corpo-espécie da nação preocupado com o controle e normalização dos sujeitos. Isso implica dizer que houve uma proliferação das tecnologias políticas que "a partir de então, vão investir sobre o corpo, a saúde, as maneiras de se alimentar e de morar, as condições de vida e todo o espaço da existência" (FOUCAULT, 2014, p. 155). E é por esse ângulo que a miscigenação se constitui no enunciado mais efetivo na construção das narrativas identitárias, quando a "identidade nacional", ou ainda, a constituição de uma brasilidade, passam a ser prioritárias na agenda do Estado.

Nesse sentido, e de acordo com Schwarcz (2012), o mestiço vira ícone nacional através de um processo de desafricanização da cultura, que será simbolicamente branqueada. Tomamos como exemplos: a feijoada, que de comida de escravo torna-se prato nacional (entre outros alimentos); a capoeira, considerada crime no código penal de 1890, passa a partir de 1942 a ser considerada modalidade esportiva; o samba é assumido como canção da brasilidade, e o carnaval se populariza; os candomblés são liberados, em 1938; o futebol associado aos negros torna-se o esporte de maior representatividade no país; e neste mesmo período a santa negra, Nossa Senhora Aparecida, é eleita padroeira do Brasil. Getúlio Vargas ainda intensificou as comemorações da Abolição da Escravatura (13 de 
maio) e instituiu o emblemático Dia da Raça, a saber dia 30 de maio. Logo, essas políticas de Estado que assimilaram a cultura negra e mestiça têm, portanto, a função de, como frisa Veiga-Neto, "trazer essas múltiplas cabeças para bem próximo, incluí-las e ordená-las num novo e cada vez maior e mais matizado campo de saberes" (2001, p. 114). Ou mesmo, agem como modo de minimizar as marcas de anormalidade e dar as condições de possibilidade a uma sociedade homogênea, o que implica tanto em "trazer os desviantes para a área da normalidade, quanto naturalizar a presença de tais desviantes no contexto social onde circulam" (LOPES, 2009, p. 160). Portanto, negros e mestiços são inclusos no discurso de pertencimento identitário, ao mesmo tempo em que anula-se o discurso racial por meio de uma exclusão das diferenças. Para tanto, entendemos este processo pela lógica da in/exclusão, ou seja, por uma zona quase que imperceptível que incluí ao mesmo passo que também é excludente quando se trata da presença negra na construção social do país.

Vale frisar que optamos pelo uso do conceito de in/exclusão, por concordar com Veiga-Neto e Lopes, de que ao

\begin{abstract}
Grafar in/exclusão aponta para o fato de que as atuais formas de inclusão e de exclusão caracterizam um modo contemporâneo de operação que não opõe a inclusão à exclusão, mas as articulam de tal forma que uma só opera na relação com a outra e por meio do sujeito, de sua subjetividade [...] in/exclusão se caracteriza pela presença de todos nos mesmos espaços físicos e pelo convencimento dos indivíduos de suas incapacidades e/ou capacidades limitadas de entendimento, participação e promoção social, educacional e laboral (VEIGA-NETO; LOPES, 2011a, p. 130-1).
\end{abstract}

Nesse sentido, a inclusão de todos na sociedade pode ocorrer em diferentes níveis de participação ou gradiente (LOPES et al., 2010), em que a mobilidade entre o incluído ou o excluído é variável pela sua participação/captura por determinados programas, ações ou mesmo práticas de governo. A assimilação política da cultura negra, além de ser uma estratégia de in/exclusão, uma vez que torna ainda mais sútil essa percepção entre incluídos e excluídos, reafirma, também, a ideia de não-conflitualidade étnico-racial, estabelecendo estratégias de governo para garantir a segurança das relações e potencializa uma narrativa do não-racismo. Ou seja, as condições de emergência para a construção discursiva do chamado mito da democracia racial, que desracializa o próprio conceito de raça e gera efeitos de poder que despotencializam o racismo, apoiado no que Florestam Fernandes chamou do "preconceito de se ter preconceito" (1965).

É na construção de uma narrativa do nãoracismo e da não-conflitualidade que a especificidade do racismo no Brasil se institui. Nessa lógica, ao branquear a população pela miscigenação, além dos caudalosos fluxos migratórios, sempre estimulados e seletivos, legitima-se uma narrativa não-racista simultânea a eliminação do negro na constituição da população (ROSA e SILVA, 2016, p. 1592).

A partir disso, é que problematizamos neste artigo o espaço educacional. Entendido como um dispositivo que potencializa a construção de saberes sobre a população. Saberes que estão diretamente imbricados em relações de poder que, de acordo com Foucault, "não há relação de poder sem constituição correlata de um campo de saber, nem saber que não suponha e não constitua ao mesmo tempo relações de poder" (1989, p. 30).

O mito da democracia racial dá condições de possibilidade para que o espaço escolar produza uma série saberes em torno, principalmente, da brasilidade, ou seja, do pertencimento identitário à nação. Até mesmo porque, como pontua Silva (2009), a Educação está entre as instituições mantidas pelo Estado-nação que estrategicamente constituem as narrativas nacionais.

No que se refere à educação, o governo Getulista protagoniza duas reformas no ensino secundário, em 1931(Decreto 19.890/31) e no ano de 1942 (por meio do Decreto-Lei 4.244), respectivamente sobre os ministérios do jurista Francisco Campos (1891-1968) e de Gustavo 
Capanema (1900-1985), este último, vale lembrar, foi responsável pela promoção da nacionalização de cerca de duas mil escolas no sul do país, quando da chamada Campanha de Nacionalização, criou o Serviço Nacional de Aprendizagem Industrial (SENAI) e o Serviço de Patrimônio Histórico e Artístico Nacional (SPHAN). Em ambos havia embutido um projeto de nacionalização que visava a condução do devir da nação e construção patriótica do corpoespécie da população. O investimento do ensino secundário estaria condicionado "à preparação das individualidades condutoras, isto é, dos homens que deverão assumir as responsabilidades maiores dentro da sociedade e da nação, dos homens portadores das concepções e atitudes espirituais que é preciso infundir nas massas, que é preciso tornar habituais entre o povo" (BRASIL, 1942). Ou seja, a educação está elencada como uma das estratégias possíveis de regulamentação da vida - deste governamento biopolítico - ao atuarem na construção das narrativas identitárias de pertencimento à nação. Narrativas que, de acordo com Stuart Hall, constituem-se como dispositivo da modernidade e condição para a formação dos Estados-nação.

\begin{abstract}
A formação de uma cultura nacional contribuiu para criar padrões de alfabetização universais, generalizou uma única língua vernacular como o meio dominante de comunicação em toda a nação, criou uma cultura homogênea e manteve instituições culturais nacionais, como, por exemplo, um sistema educacional nacional. Dessa e de outras formas, a cultura nacional se tornou uma característica-chave da industrialização e um dispositivo da modernidade (2014, p. 30).
\end{abstract}

O saber histórico, por sua vez, é estratégico nesta função. A valorização da história brasileira e de um projeto moral e cívico reforçou o ideário da fábula das três raças - para tomar a expressão do antropólogo Roberto Da Matta (1981). A Reforma do ensino secundário de 1931 englobou na disciplina de História da Civilização os conteúdos de História Geral e do Brasil. "Gradualmente, por meio de vários atos legais, a História do Brasil adquiriu autonomia, quando a Reforma de 1942 restabeleceu em caráter permanente a separação entre a História Geral e do Brasil, aumentando consideravelmente a carga horária da disciplina no curso ginasial" (ABUD, 1998) e acrescentando o ensino moral e cívico. A segunda reforma do ensino no Governo Vargas, estará fundamentada, segundo seu promotor, Gustavo Capanema, a partir de

um ensino patriótico por excelência, e patriótico no sentido mais alto da palavra, isto é, um ensino capaz dar aos adolescentes a compreensão da continuidade histórica da pátria, a compreensão dos problemas e das necessidades, da missão e dos ideais da nação, e bem assim dos perigos que a acompanhem, cerquem ou ameacem, um ensino capaz, além disto, de criar, no espírito das gerações novas, a consciência da responsabilidade diante dos valores maiores da pátria, a sua independência, a sua ordem, o seu destino (BRASIL, 1942).

Nesse caminho, que as ciências sociais estão imbricadas na construção dos saberes e, tão logo, vão colaborar para que o Estado consiga legitimar suas relações de poder. E a História - mais precisamente as narrativas históricas -são produtoras de identidades nacionais, por vezes sólidas e homogêneas, e, também, como campo de práticas legitimadoras de discursos de verdade. Verdades que, de acordo com Foucault (2012, p. 224), não podem ser dissociadas do poder e de mecanismos de poder, "porque essas produções de verdade têm, elas próprias, efeitos de poder que nos unem, nos atam", por exemplo, em torno de um pertencimento identitário.

No processo de homogeneização do país, em que a educação foi peça chave, constituíram-se discursos curriculares calcados na contribuição das raças para a composição das narrativas da nação. De acordo com Abud (1998), sobre a análise dos programas e manuais que orientaram o ensino secundário no segundo governo Vargas, negros e indígenas foram incorporados às narrativas a partir de suas contribuições sociais. Aos indígenas reservou-se que "o componente de nobreza da nossa formação viria do índio, que não teria aceito a escravidão, que enfrentava bravamente os obstáculos da floresta e os inimigos". Já aos negros, coube o discurso em torno de uma presença transitória e futuramente branqueada. 
Ao outro elemento formador do brasileiro, dominado pelo colonizador, o negro, os livros dedicavam pouco espaço como objeto de Etnografia/Antropologia. Ele sempre era tratado como mercadoria, produtor de outras mercadorias. Enquanto ao índio se conferia o estatuto de contribuição racial, os livros didáticos salientavam a importância do africano para a vida econômica do país, mas procuravam mostrar que a negritude estava sendo diluída pela miscigenação (ABUD, 1998).

A narrativa da nação, portanto, (re)produzida no espaço escolar, funciona como cimento constitutivo desta população que se visa depurar, selecionar e integrar seus membros num corpoespécie da população. Foucault, na aula de 17 de março de 1976, do curso publicado sob o título Em Defesa da Sociedade, chama a atenção que "a biopolítica lida com a população, e a população como problema político, como problema a um só tempo científico e político, como problema biológico e como problema de poder" (FOUCAULT, 2010, p. 206). Deste modo, os processos que antes eram direcionados ao indivíduo tiveram de converter-se para um poder-saber às massas, com a intenção de inserir os sujeitos nas estruturas do Estado-nação, inclusive a população negra que, como vimos, a partir de cidadão liberto, com o fim do período escravista, tomou o centro dos debates acerca do processo de nacionalização.

Quando mencionamos o silêncio em torno do racismo, a partir da construção discursiva do mito da democracia racial, também concebemos a escola como esse espaço de disciplinamento e de normalização em que a raça foi tratada sobre a perspectiva da diversidade - inclusive, da celebração dessa diversidade. A inclusão do negro em narrativas que ignoraram os preceitos racistas, alavancados com a escravidão e no pós-abolição, deram condições para que estes sujeitos fossem postos em espaços in/exclusivos. Estrategicamente a democracia racial estabeleceu uma processo que inclui o negro pela sua exclusão a partir de duas perspectivas: seja pelo desaparecimento, via projeto de branqueamento, ou pela inclusão em zona de indecidibilidade (em que não se é branco e nem negro), que é a mestiçagem. Logo, e não sem sentido, que o espaço escolar (re)produza essa "zona de conforto" criada em torno das tensões raciais apoiada nessa lógica de in/exclusão.

O mito da democracia racial como dispositivo de neutralização do racismo e mesmo de estruturação de uma lógica social não-conflituada racialmente tem sido objeto de crítica e desconstrução acadêmica desde os anos 1950 e, mais recentemente, desde o final dos anos 1970, com a crise da ditadura militar, com os movimentos sociais antirracismo e com o Movimento Negro Unificado (1978). Desde o governo FHC assistimos a intensificação da crítica à democracia e o crescimento do protagonismo do MNU no sentido de institucionalizar políticas de combate ao racismo. Tanto que, em 1996, na abertura do Seminário Multiculturalismo e Racismo: o papel da ação afirmativa nos estados democráticos contemporâneos, evento promovido pelo Ministério da Justiça, que reuniu pesquisadores, autoridades internacionais e representantes do Movimento Negro, o então Presidente Fernando Henrique Cardoso em pronunciamento declara reconhecer que as desigualdades no Brasil são efeitos do racismo.

Neste mesmo ano, instituí-se uma nova abordagem sobre a temática racial - a construção dos Parâmetros Curriculares Nacionais (PCN's), especificamente o tema transversal da Pluralidade Cultural - quando a questão da diversidade percorrerá novamente, e com intensidade, o campo da educação. O documento destinado a orientar os currículos escolares de forma mais homogênea e unificadora é publicado concomitante a instauração da nova Lei de Diretrizes e Bases da Educação, a LDB 9394/96.

O tema da Pluralidade Cultural deverá atravessar as práticas educacionais nas mais variadas disciplinas, tanto que a construção dá-se por uma série de saberes autorizados, como o jurídico, o histórico, o geográfico, o sociológico, o antropológico, o psicológico e o saber pedagógico. Os Parâmetros reconhecem como a ideia do não-preconceito é 
constitutiva da sociedade e responsável pela dificuldade histórica de lidar com as temáticas da discriminação étnico-racial. Segundo o documento, "o País evitou o tema por muito tempo, sendo marcado por 'mitos' que veiculam uma imagem de um Brasil homogêneo, sem diferenças, ou, em outra hipótese, promotor de uma suposta 'democracia racial'." (PCN, 2001, p. 22).

Desta forma, reproduzimos aqui alguns dos objetivos propostos pelos Parâmetros na temática da Pluralidade Cultural, a fim de chamar atenção para como a problemática da democracia racial será contornada pela lógica da diversidade: - conhecer a diversidade do patrimônio etno-
cultural brasileiro, tendo atitude de respeito
para com pessoas e grupos que a compõem,
reconhecendo a diversidade cultural como um
direito dos povos e dos indivíduos e elemento
de fortalecimento da democracia;

- valorizar as diversas culturas presentes na constituição do Brasil como nação, reconhecendo sua contribuição no processo de constituição da identidade brasileira;

- reconhecer as qualidades da própria cultura, valorando-as criticamente, enriquecendo a vivência de cidadania;

- desenvolver uma atitude de empatia e solidariedade para com aqueles que sofrem discriminação;

- repudiar toda discriminação baseada em diferenças de raça/etnia, classe social, crença religiosa, sexo e outras características individuais ou sociais;

- exigir respeito para si, denunciando qualquer atitude de discriminação que sofra, ou qualquer violação dos direitos de criança e cidadão;

- valorizar o convívio pacífico e criativo dos diferentes componentes da diversidade cultural;

- compreender a desigualdade social como um problema de todos e como uma realidade passível de mudanças.

As palavras em destaque (grifos nossos), caso dos verbos valorizar, reconhecer e apenas repudiar atos discriminatórios são meios de despotencializar os efeitos do racismo cotidiano que impera nas relações étnico-raciais do Brasil e que a partir de então teriam de ser problematizados no espaço escolar. Por conseguinte, atentamos que tais objetivos são proposições que deixam de indagar as relações de poder e os processos de hierarquização identitários, e além do mais, segundo Tomaz Tadeu da Silva (2014, p. 98), geralmente apenas resultam em novas dicotomias, "como a do dominante tolerante e do dominado tolerado". Ou que, como frisa Marcon, sobre a perspectiva da diversidade e pedagogicamente imbrincada, "esta perspectiva pode resultar em situações complicadas, como a afirmação da identidade de cada grupo, valores, crenças, padrões de conduta próprios, sem uma análise mais global da constituição e das relações que os diferentes grupos constroem e reconstroem" (2009, p. 52).

Isto posto, não podemos deixar de ponderar que tais documentos que destinam-se a orientar os currículos são estratégias de normalização dos sujeitos e das relações identitárias. Se concordamos que a educação produz e exerce um governamento biopolítico sobre os sujeitos - regulando-os a fim convenientes - temos de pensá-la como produtora de identidades e entender que esta é composta por uma série de discursos pelos quais os sujeitos serão ordenados no espaço e sobre quais narrativas serão constituídos, ora enquanto identidade de pertença ora enquanto diferença (como "os outros", os que estão fora).

Atentamos, ademais, que os referidos documentos são produzidos a partir de uma perspectiva identitária essencialista, tida como natural, desejável, única, que, no caso, é a calcada no branco-europeu. A educação, neste caso, seria o modo autorizado de trazer o "outro" para próximo da cultura operante. Nesta composição de espaços raciais, dentro das narrativas, é que entendemos o tensionamento do conceito de in/exclusão - uma linha tênue que organiza e hierarquiza os sujeitos que estão ora inclusos e ora excluídos em um basilar discurso do não-racismo.

\section{DCN'S e os processos de in/exclusão nos currículos escolares}

As Diretrizes Curriculares Nacionais foram elaboradas no ano 2004, a fim de substituir os Parâmetros Curriculares Nacionais, a partir de uma abordagem "posta pela emergência da atualização 
das políticas educacionais que consubstanciem 0 direito de todo brasileiro à formação humana e cidadã e à formação profissional, na vivência e convivência em ambiente educativo (2013, p. 7). Antes de tudo, vale frisar, que ambos os documentos - PCN's e DCN's - são resultados de duas décadas (1990 e 2000) de intensa atividade dos movimentos negros articulados em prol de políticas públicas de promoção da igualdade racial sustentados, vale dizer, por volumosas pesquisas que problematizaram as relações raciais, o racismo e a etnicidade no país.

As Diretrizes propõem um currículo comum às instituições de ensino do país, mesmo atestando o respeito à particularidade de cada local e interesses específicos. O documento alavanca propostas mais específicas a grupo que tendemos a chamar de "minorias". As Diretrizes Curriculares orientam em diversas modalidades curriculares, entre elas, 0 ensino para a Educação Especial; de Jovens e Adultos em estabelecimentos penais; para a Educação no Campo; Indígena; para atender a grupos Nômades; Quilombolas e, por fim, de nosso interesse neste artigo, o ensino para as relações étnico-raciais, especificamente, as Diretrizes Curriculares Nacionais para a Educação das Relações Étnico-Raciais e a para o Ensino de História e Cultura Afro-Brasileira e Africana.

No documento em questão, a educação é concebida como o meio mais propício para a superação do racismo e a promoção racial e, do mesmo modo, como um "projeto de nação" (DCN's, 2013, p. 9). Ou seja, como estratégia para a regulação e a condução dos sujeitos e do bem estar social. Foucault salienta na aula de 17 de março de 1976, ao referir-se à emergência da biopolítica como nova racionalidade de poder, que esta age sobre um "equilíbrio global" (2010, p. 209), ou ainda, levando em consideração "fenômenos coletivos, que só aparecem com seus efeitos econômicos e políticos, que só se tornam pertinentes no nível da massa" (2010, p. 206). É, nesse sentido, que um currículo comum à nação age sobre uma massa de sujeitos e sobre o que eles tem de global.
Thomaz Popkewitz (2011) chama atenção que o currículo cria dois níveis de regulação: sobre os conteúdos a serem selecionados e, segundo, como o currículo é capaz de posicionar os sujeitos no mundo. O primeiro nível de regulação trata daquilo que deve ser conhecido, ou seja, quando "certas informações são selecionadas dentre uma vasta gama de possibilidades. Essa seleção molda e modela a forma como os eventos sociais e pessoais são organizados para a reflexão e a prática (p. 191). E, no segundo, uma regulação que posiciona os sujeitos no mundo dentro de regras, padrões, e porque não, dentro de uma História

Não se trata apenas de que notas são obtidas e diplomas são concedidos. O processo de escolarização incorpora estratégias e tecnologias que dirigem a forma como os estudantes pensam sobre o mundo em geral e sobre seu eu no mundo (...) Podemos ver as práticas escolares como formas politicamente sancionadas para os indivíduos organizarem suas visões do "eu". (POPKEWITZ, 2011, p. 191).

O currículo precisa ser entendido, desta forma, como estratégico na construção das narrativas identitárias étnico-raciais, como estruturante dos espaços, das linhas de normalidade, da relação Nós $x$ Outro e, principalmente, na lógica da in/exclusão. Seja na escolha dos conteúdos e abordagens ou seja, e principalmente, pela posição que estes sujeitos serão postos nestas relações - que vale dizer, são relações de poder-saber - que os tensionamentos sobre incluídos e excluídos serão condicionados.

As condições de emergência dos discursos raciais nos currículos escolares são atravessadas por uma ordem histórica, por contextos específicos e, logo, produzem, como vimos acima, saberes diversos, em dados momentos e para fins convenientes. As Diretrizes para a educação das relações étnico-raciais nos colocam diante da construção de novas narrativas de inclusão. O uso do conceito de pluralidade na construção dos Parâmetros Curriculares Nacionais foi condição suficiente para atender a demanda de um país que, pela primeira vez, trataria oficialmente do racismo no espaço escolar. 
Já o que emerge em 2004, com as Diretrizes Curriculares Nacionais para a Educação das Relações Étnico-Raciais e para o Ensino de História e Cultura Afro-Brasileira e Africana, é uma tratativa mais racialista sobre o assunto. O documento prediz que "o Estado e a sociedade tomem medidas para ressarcir os descendentes de africanos negros, dos danos psicológicos, materiais, sociais, políticos e educacionais" (2013, p. 498), danos, que segundo as Diretrizes, são oriundos do sistema escravista, da política de branqueamento e da manutenção de privilégios a determinados grupos. Vale frisar também que as Diretrizes já emergem amparadas por uma série de políticas públicas, como a Lei 10.639 de 2003 que prevê incluir "o estudo da História da África e dos Africanos, a luta dos negros no Brasil, a cultura negra brasileira e o negro na formação da sociedade nacional, resgatando a contribuição do povo negro nas áreas social, econômica e política pertinentes à História do Brasil", reservadas as disciplinas de Educação Artística, Literatura e História e institui a data de 20 de Novembro como o Dia da Consciência Negra.

Não é de nosso interesse marcar como certo ou errado as abordagens propostas pela materialidade dos DCN's, mas, no entanto, problematizar como determinados regimes de verdades são produzidos pela área educacional no que tange às questões étnico-raciais, as quais são atravessadas pela ordem in/exclusiva. Isso porque 0 documento toma a escola como campo de luta e como local de produção de sujeitos - ou mesmo, de novos modos de subjetivação.

As Diretrizes para a educação das relações raciais acreditam no papel político da escola, e que este espaço deve se posicionar contra qualquer forma de discriminação. Segundo o documento,

A escola tem papel preponderante para eliminação das discriminações e para emancipação dos grupos discriminados, ao proporcionar acesso aos conhecimentos científicos, a registros culturais diferenciados, à conquista de racionalidade que rege as relações sociais e raciais, a conhecimentos avançados, indispensáveis para consolidação e concerto das nações como espaços democráticos e igualitários (DCN's, 2013, p. 501).

A escola é, portanto, espaço de legitimação de verdades. Quando nela circulam, e de forma privilegiada, em dadas condições históricas específicas, discursos acerca das narrativas raciais e de nacionalidade, o que existe são produções de verdade e novas relações de poder-saber sendo legitimadas. Veiga-Neto (2001) frisa que a escola é espaço privilegiado para reconhecermos transformações que estão ou ainda acontecerão, bem como local para implementação de mudanças na lógica social.

Em vista disso, a desconstrução do mito da democracia racial também é ponto chave na elaboração das Diretrizes:

buscando-se especificamente desconstruir o mito da democracia racial na sociedade brasileira; mito este que difunde a crença de que, se os negros não atingem os mesmos patamares que os não negros, é por falta de competência ou de interesse, desconsiderando as desigualdades seculares que a estrutura social hierárquica cria com prejuízos para os negros (DCNs, 2013, p. 499).

E a partir desta perspectiva que o documento fará uso do termo inclusão, por exemplo, ao prever:

Precisa, o Brasil, país multi-étnico e pluricultural, de organizações escolares em que todo se vejam incluídos, em que Ihes seja garantido o direito de aprender e de ampliar conhecimentos, sem ser obrigados a negar a si mesmos, ao grupo étnico/racial a que pertencem e a adotar costumes, idéias e comportamentos que lhes são adversos (DCN's, 2013, 503).

Ao analisarmos, na proposição das diretrizes para a educação das relações étnico-raciais, as ações educativas de combate ao racismo e a discriminações, percebemos orientações em torno da valorização das expressões culturais (arte e dança) e do patrimônio afro-brasileiro; o conhecimento de datas significativas da História negra, de personagens e da contribuição da África e dos afro-brasileiros na construção da História 
brasileira. Isso sobre uma ampla inclusão desses assuntos na educação básica e nos cursos superiores de licenciatura e no próprio planejamento e normativas nos estabelecimentos de ensino do Brasil.

Estão postas aqui as novas condições para a produção das narrativas históricas nacionais sobre a presença do negro e da contribuição africana na História do país. Há mais de uma década que os estabelecimentos de ensino, orientados pelas Diretrizes Curriculares Nacionais para a Educação das Relações Étnico-Raciais e para o Ensino de História e Cultura Afro-Brasileira e Africana, estão produzindo novos processos de subjetivação e estruturando novas relações de poder e reorganizando identidades. Para Siqueira (2015, p. 45-6), o que se produz são novos discursos que

reordenam as dinâmicas dos grupos culturais, sociais e étnicos de modo intangível e estratégico, uma vez que a lógica, a partir da qual esse processo de agenciamento se opera, pressupõe a releitura a respeito das ancestralidades e/ou identidades étnicas que carrega em si, novos discursos naturalizados e imunes à própria historicização sobre o pertencimento identitário.

Nesse sentido, as Diretrizes (2013, p. 502) colocam que todos, "negros e não negros, além de ter acesso a conhecimentos básicos tidos como fundamentais para a vida integrada à sociedade, exercício profissional competente, recebam formação que os capacite para forjar novas relações étnicoraciais". Assim, estas novas dinâmicas, mencionadas por Siqueira, podem ser pensadas como inclusivas no sentido de visarem à colocação dos sujeitos negros em novos espaços - novas organizações sociais. Mas, também, como dinâmicas de exclusão, até mesmo porque incluir em um (ou mais) espaço(s) implica, de alguma forma, excluir de outro(s), bem como, significa que a inclusão em novas narrativas identitárias ao mesmo tempo é a exclusão de outros processos identitários até então estruturados.

Neste processo de (re)construção de saberes históricos sobre os sujeitos negros, atentamos para o enunciado da diversidade que perpassa os currículos escolares. Chamamos atenção para o uso dos verbos valorizar, respeitar e conhecer como indicativos do enunciado da diversidade que prepondera nas Diretrizes, e que nos levam a concordar com Skliar e Duschatzky (2001) quando dizem que as políticas educativas e culturais acerca da diferença enleiam-se em discursos e práticas ora politicamente corretas ora confusas. Politicamente corretas em razão de atenderem a uma demanda da contemporaneidade em revisitar as construções identitárias. Confusas porque concebem os conceitos de diferença $e$ diversidade como coexistentes e estabelecem as identidades como essencializadas, por vezes, negando toda uma constituição identitárias que é miscigenada, sincrética e tão pouco fixa.

Thoma (2004, p. 1) reforça que nas atuais políticas, sejam elas sociais e/ou educacionais, não há distinção entre diversidade e diferença, em que a primeira "é entendida como uma característica das sociedades modernas a ser aceita e tolerada, ao passo que a diferença é uma construção social, política, histórica e linguística imbrincada em relações de poder que afetam a cada um e a todos nós". De acordo com a autora, falar em diversidade é um modo de apagar as diferenças e levar ao "ocultamento dos conflitos sociais, pois entende os chamados excluídos como sujeitos pertencentes a uma categoria homogênea, cujos traços de identidade resumem-se ao pertencimento a um determinado grupo (mulheres, negros, velhos, homossexuais, deficientes)" (THOMA, 2004, p. 1).

Por assim ser, o enunciado da diversidade acaba por sucumbir qualquer tratativa a respeito da problemática da diferença. O que nos é colocado são estratégias de regulação da diferença - entre elas, a valorização do diverso. Quando os Parâmetros e as Diretrizes propõem que a identidade do "outro" seja conhecida e valorizada, eles de alguma forma partem do princípio de que se fala de identidades fixas, dando assim condições para a construção de uma série de estereótipos sobre ao diferença. Duschatzky e Skliar (2001, p. 124) nos ajudam a entender melhor essa transmutação da diferença em diversidade ao colocarem que "a alteridade, para poder fazer parte da diversidade cultural bem entendida e aceitável, 
deve despir-se, des-racializar-se, des-sexualizar-se, despedir-se de suas marcas de identidade; deve, em outras palavras, ser como as demais". Estes processos de "deixar de ser algo" são estratégias de segurança em favor de uma unidade nacional, principalmente no que tange às questões raciais. Historicamente, como apresentamos acima, houve a transformação da cultura negra em prol da brasilidade e o incentivo a mestiçagem como estratégia para que se chegasse a um país branco, ou seja, enquanto processos de desracialização desses sujeitos.

Nessa lógica, o Estado faz uso estratégico do multiculturalismo, a partir de uma vertente conservadora, na construção das políticas públicas. O uso constante dos verbos valorizar, respeitar e tolerar são enunciados da diversidade cultural "que autorizam que os outros continuem sendo esses outros", contudo, a partir de então "em um espaço de legalidade, de oficialidade" (DUSCHATZKY; SKLIAR, 2001, p. 130), ou seja, dentro de uma curva de normalidade - em que as identidades, as expressões culturais, fiquem fechadas em seus já prédeterminados espaços. Logo, uma lógica inclusiva e concomitante de exclusão. O que queremos dizer, e sugerir como problemática quando se trata do ensino de História Étnico-Racial, é que o discurso que prima pela tolerância dilui modos de enfrentamentos identitários, não permite questionamentos e age em prol do bem estar social - por conseguinte, é um discurso cômodo para o Estado e para a escola. É, ao mesmo tempo, um discurso que ajuda a formular a classificação e a hierarquização entre "nós" e os "outros".

Quando as Diretrizes preveem que todos devem ser incluídos, mas frisa que "sem ser obrigados a negar a si mesmos, ao grupo étnico/racial a que pertencem e a adotar costumes, ideias e comportamentos que lhes são adversos" (DCN's, 2013, p. 503), ou seja, nos coloca diante da autorização de que mesmo que pela perspectiva da inclusão há uma separação étnico-racial e a ideia de identidades imóveis. Logo, o que os currículos escolares produzem são novas narrativas acerca dos negros calcadas, novamente, na ideia de não- conflitualidade. São proposições que deixam de indagar as relações de poder e os processos de hierarquização identitários. Silva aponta para algumas estratégias pedagógicas que circundam o campo das diferenças. Em uma delas, o autor classifica na ordem de uma estratégia "liberal", que é manter a boa vontade perante o diverso. Uma segunda estratégia diz-se "terapêutica", em que a "diversidade é 'natural' e boa, mas atribui a rejeição da diferença e do outro a distúrbios psicológicos" (SILVA, 2014, p. 98); no entanto, Silva pontua, como estratégia pedagógica mais comum nos espaços escolares, a que produz o outro como o "exótico", o "curioso" (basta pensarmos na formas como, por exemplo, celebramos nas escolas as datas comemorativas como o Dia do índio e da Consciência Negra, numa verdadeira construção de estereótipos exóticos, para não dizermos, bizarros), o que, para ele,

Além de não questionar as relações de poder envolvidas na produção da identidade e da diferença culturais, essa estratégia as reforça, ao construir o outro por meio das categorias do exotismo e da curiosidade. Em geral, a apresentação do outro, nessas abordagens, é sempre o suficientemente distante, tanto no espaço quanto no tempo, para não apresentar nenhum risco de confronto e dissonância (SILVA, 2014, p. 99).

O que estas estratégias refletem é a noção de controle de risco - a seguridade sobre as relações. $O$ governamento biopolítico produzido no âmbito escolar garante ao Estado um controle seguro e calculado sobre a noção de risco posto diante dos conflitos raciais. Foucault (2008a) salienta que a garantia de segurança dá-se por uma série de técnicas de vigilância dos indivíduos, de diagnósticos mentais e patológicos - ações perfeitamente cabíveis ao espaço escolar.

As Diretrizes estabelecem que a questão racial perpasse a constituição de sujeitos desde a infância até a formação adulta. Nesse caso, a partir de novas narrativas identitárias se produz novos conjuntos de regimes de verdade sobre as relações étnico-raciais (o que também já era a proposição dos Parâmetros Curriculares Nacionais). Por conseguinte, é necessário analisar que quando um agente 
autorizado do Estado, no caso o Ministério da Educação, regula os modos de construção das narrativas identitárias acerca de um grupo constitui sobre estes uma relação de poder calcada, primeiro, no imperativo da inclusão e segundo, em estratégias de regulação da conflitualidade.

Incluir é a estratégia mais segura de regulação, ao passo que coloca todos sobre o controle do Estado. Ao pensar as questões raciais, entendemos que quando o país desloca o discurso calcado no mito da democracia racial, da nãoconflitualidade - que era relativamente cômodo e seguro - para o da produção e aceitação do outro tende a produzir novos modos de segurança e "regulação da conflitualidade". As políticas públicas que atendem através de um discurso multiculturalista embasado na diversidade produzem sujeitos inclusos em espaços já pré-determinados (espaços novos, diga-se de passagem, incluídos nos currículos escolares, universidades, em cargos públicos) e, no entanto, excluídos de suas diferenças.

\section{Considerações finais}

Este artigo não teve como objetivo propor receitas prontas sobre a educação étnico-racial, especialmente na área da História. Mas sim, problematizar a partir das legislações vigentes as novas narrativas que estão sendo produzidas, via currículos escolares, sobre a presença do negro na composição nacional do país.

Analisamos esses novos ordenamentos do saber sobre o discurso contemporâneo da inclusão calcado no enunciado da diversidade. Se as Diretrizes reconhecem a escola como espaço que tanto silenciou as práticas racistas, ou mesmo se isentou de abordá-las, inegavelmente, o documento, tratado aqui como materialidade discursiva, é base importante de constituição de novos sujeitos e novos saberes autorizados sobre as narrativas identitárias em torno da nacionalidade.

A diversidade aproxima, em linhas imaginariamente divisórias, o "nós" do "outro". O "outro" não é só mais um desconhecido, ele passa, numa onda politicamente correta, a ocupar a sala de aula, o comercial publicitário, entre outros, mas ele é deslegitimado da sua diferença, porque, essa sim, pode não ser segura. O sujeito negro é incluso pela diversidade, ao mesmo tempo que é excluído da diferença e, nesse sentido, é que temos de pensar o papel estratégico da educação na construção dessas novas relações de poder em torno das narrativas étnico-raciais.

\section{Referências}

ABUD, Kátia Maria. Formação da Alma e do Caráter Nacional: Ensino de História na Era Vargas. In: Revista Brasileira de História, vol. 18, n. 36, São Paulo: 1998. Disponível em: www.scielo.br. Acesso em: jul. de 2016.

BRASIL. Decreto n 19.890 , de 18 de abril de 1931. Dispõe sobre a organização do ensino secundário.

Decreto-Lei $n^{\circ}$ 4.244, de 9 de abril de 1942. Exposição de motivos: Lei Orgânica do Ensino Secundário. Disponível em: www2.camara.leg.br. Acesso em: jul. 2016.

Parâmetros Curriculares Nacionais: Pluralidade Cultural e Orientação Sexual. 3 edi. Ministério da Educação. Brasília, 2001.

Lei $\mathrm{n}^{0}$ 10.639, de 9 de janeiro de 2003. Disponível em: www.planalto.gov.br.

Lei $\mathrm{n}^{\circ} 11.645$, de 10 de março de 2008. Disponível em: www.planalto.gov.br

Diretrizes Curriculares Nacionais para a Educação das Relações Étnico-raciais e para o Ensino de História e Cultura Afro-brasileira e Africana. Ministério da Educação, Brasília: 2013.

DA MATTA, Roberto. Relativizando: uma introdução à Antropologia Social. Petrópolis: Vozes, 1981.

DUSCHATZKY, Silvia. SKLIAR, Carlos. O nome dos outros. Narrando a alteridade na cultura e na educação. In: LARROSA, Jorge. SKLIAR, Carlos (org.). Habitantes de Babel: políticas e poéticas da diferença. Belo Horizonte: Autêntica, 2001.

FERNANDES, Florestan. A integração do negro na sociedade de classe. São Paulo: Cia Editora Nacional, 1965.

FOUCAULT, Michel. Vigiar e Punir. Petrópolis: Vozes, 1989.

Segurança, Território e População. São Paulo: Martins Fontes, 2008. 
Em defesa da sociedade. São Paulo: Martins Fontes, 2010

Ditos \& Escritos IV: estratégia poder-saber. Rio de Janeiro: Forense, 2012.

História da Sexualidade: a vontade de saber. São Paulo: Paz e Terra, 2014.

HALL, Stuart. A identidade cultural na pósmodernidade. Rio de Janeiro: Lamparina, 2014.

LACERDA, J. B. de. Informações prestadas A. S. Ex Ministro da Agricultura Dr. Pedro de Toledo. Rio de Janeiro, RJ: papelaria Macedo, 1912.

LOPES, Maura Corcini. Políticas de Inclusão e governamentalidade. In: Educação \& Realidade, Porto Alegre, v. 34, n. 2, mai/ago. 2009, p. 153169.

Inclusão e biopolítica. Caderno IHU Ideias, ano 8, n. 144, 2010.

MARCON, Telmo. Multiculturalismo, intercultura e políticas educacionais. In: Espaço Pedagógico, Passo Fundo, v.16, n. 2, jul/dez. 2009, p. 48-61.

POPKEWITZ, Thomaz S. História do Currículo, regulação social e poder. In: SILVA, Tomaz Tadeu (org.). $O$ sujeito da educação: estudos foucaultianos. Petrópolis: Vozes, 2011.

SCHWARCZ, Lilia Moritz. Nem preto nem branco, muito pelo contrário: cor e raça na sociabilidade brasileira. $1^{\mathrm{a}}$ edição. São Paulo: Claro Enigma, 2012.

SILVA, Mozart L. Educação intercultural e hibridismo identitário no Brasil: limites do multiculturalismo. In: SILVA, M. L. HILLESHEIM, B. OLIVEIRA, C. J (Org.). Estudos Culturais, Educação e Alteridade. Santa Cruz do Sul: Edunisc, 2009.
SILVA, Tomaz Tadeu. A produção social da identidade e da diferença. In: SILVA, Tomaz Tadeu (org.). Identidade e Diferença: a perspectiva dos Estudos Culturais. Petrópolis: Vozes, 2014.

SIQUEIRA, Carolina de Freitas Côrrea. Narrativa histórica, cultura afro-brasileira e governamento biopolítico. 2015. Dissertação (Mestrado em Educação) - Programa de Pós-graduação em Educação da Universidade de Santa Cruz do Sul (UNISC), Santa Cruz do Sul, 2015.

THOMA, Adriana. Sobre a proposta de Educação Inclusiva: notas para ampliar o debate. Revista Educação Especial, v. 23, 2004.

ROSA, Camila Francisca e SILVA, Mozart Linhares. Biopolítica, Raça e in(ex)clusão no Brasil. In: V Colóquio Latino-Americano de Biopolítica, III Colóquio Internacional de Biopolítica e Educação, XVII Simpósio Internacional IHU - Saberes e Práticas na Constituição dos Sujeitos na Contemporaneidade. 2015, São Leopoldo, RS. Anais (on-line). São Leopoldo: Casa Leiria, 2016, p. 1589- 1598.

VEIGA-NETO, Alfredo. Incluir para excluir. In: LARROSA, J. \& SKLIAR, C (org.). Habitantes de Babel: políticas da diferença. Belo Horizonte: Autêntica, 2001.

VEIGA-NETO, Alfredo e LOPES, Maura Corcini. Inclusão, Exclusão, in/exclusão. Revista Verve, vol. 20, p. 121-135, 2011. 